THURSDAY, OCTOBER I7, I889.

THE ELEMENTARY TEACHING OF SCIENCE.

DERHAPS the most important event in the Chemical Section at Newcastle was the presentation of a second Report (the first part of which we print elsewhere) by the Committee ${ }^{1}$ appointed "to inquire into and report upon the present methods of teaching chemistry." It is a remarkable fact that the daily Press in general has made only the barest possible reference to the Report or to the animated discussion which followed its reading; although, as the Times points out, "there is a Committee attached to Section $B$, the professed purpose of which is to inquire into and report upon the teaching of chemistry; the truth is, however, that it involves the wide question of science teaching in general. The national importance of such an inquiry is evident, and it behoves all the Sections to take an interest in it."

At the Bath meeting the Committee reported on the condition of chemical teaching in the principal public schools of Great Britain and Ireland, their Report being founded upon information obtained from the principals, head masters, and science masters of these schools. This Report demonstrated the existence of a most unsatisfactory state of things. It proved unquestionably that physical science still occupies a very subordinate position in most of our public schools, and it appears that this is the result, in no small measure, of the manner in which it is taught. The attempt to cram the minds of boys with a conglomeration of chemical facts under the name of "science" has reached a crisis; and head masters, and even some parents, are beginning to feel, and to say in so many words, that science teaching, which has been on its trial for so many years, has failed to produce the educational effect which was expected from it. The teachers, while complaining of the various difficulties which surround their attempts to teach chemistry, e.g. insufficient time and laboratory accommodation, frankly admit that the methods at present employed in teaching the science are for the most part ineffective, and that to this circumstance may be attributed, in the majority of instances, the inferior position which is assigned to the subject in the school curriculum, Partly in self-justification, and partly as an explanation of the continued existence of these abortive methods, teachers have drawn attention to the requirements of the various examining bodies by which their hands are tied. It is rare to find the science master who is free to break away from conventional lines, and to use chemistry in illustration of the scientific method of questioning Nature, instead of relating to his boys the properties of all the elements from hydrogen to uranium, and by a system of laboratory drill instructing them how to "test" rare compounds or absurdly complex mixtures. Of the few examinational schedules which are likely to assist the teacher in making his elementary instruction in science most useful as an educational instrument, special mention

Consisting of Prof. H. E. Armstrong, F.R.S., Prof. W. R. Dunstan (Secretary), Dr. J. H. Gladston,, F.R.S., Mr. A. G. Vernon Harcourt, F.R.S., Prof. McLeod, F.R.S., Prof. Meldola, F.R.S., Mr. M. M. Pattison Muir, Mr. W. A. 'Shenstone, Prof. Smithells, and Mr. G. Stallard. (Chairman) VOL. XL.-NO. 1042. may here be made of the syllabus of physiography issued by the Science and Art Department, having been drawn up by Mr. Norman Lockyer, and of the syllabus issued by the same Department for the "Alternative First Stage in Chemistry" (why should not this be made the "First Stage in Chemistry"?), which was compiled by two members of the present Committee, Sir Henry Roscoe and Dr. Russell.

The Committee thought that they might be able to do something towards a reorganization of elementary instruction in science ; in fact several teachers had pointed out that the Committee were most favourably constituted for taking such action, and that they would doubtless be able to induce examining Boards to reconsider their present regulations.

About the middle of the present century two schools of educational authorities were actively engaged in propagating their views. The one school contended that the object of primary education should be to teach those subjects which can be practically applied in after life, while the other asserted that its main object should be to develop the faculties and not merely to store the mind with knowledge. Chemistry, no doubt, was introduced into the school curriculum chiefly to satisfy the demands of the first theory, but nevertheless it may equally well serve the purposes of the second. The mental discipline afforded by chemical investigation in developing the powers of observation and inference, and in teaching the correct use of hypothesis, is not less conspicuous than the many applications of which the science is susceptible both in industrial and "common" life. Happily, of late years, a fusion of these two theories has taken place, and agreement has very generally been reached on two important points. First, that the main purpose of elementary education should be to train the intelligence. In this sense "education is a high word-it is nothing less than the formation of mind." Secondly, it is admitted that before a man can apply science to practice he must be familiar with its methods, his mind must be able habitually to perform those logical processes which accurate thought demands. We are now fairly unanimous in the opinion that it should be the endeavour of elementary education to develop habits of correct observation and reasoning, so that in later life the more advanced knowledge of science, which will subsequently have been acquired, may be intelligently applied to the solution of social and industrial problems.

In the opinion of the Committee, this training of the intelligence can be readily effected by a properly arranged course of elementary instruction in physical science. This fact is, however, not recognized by the majority of educational authorities, since chemical teaching, which represents physical science in most schools, has hitherto been chiefly directed to the acquisition of a vast number of chemical facts. But the "learning of true propositions, dogmatically delivered, is not science," and does not produce any mental effect that cannot as well be reached by many other paths, e.g. the multiplication table and the facts of English history. So far, the public in this country have had very few opportunities of judging of the educational value of physical science, and it is to be feared that they have not yet sufficiently recognized the truth and significance of Herbert Spencer's definition of C C 
science as "trained and organized common-sense." which implies that those same mental processes whose use has led to great scientific discoveries are also applicable to even the commonest affairs of life with equally successful results. In order to make chemistry subservient to the needs of mental education, it is necessary to depart almost entirely from the usual method of teaching it, which is better adapted for the subsequent training of those comparatively few students who intend to follow chemistry as a profession. Instead of attempting to travcrse the greater part of the science, the teaching must be restricted to those portions of it which best exemplify the scientific method of investigation; and it should, as far as possible, have reference to objects which are more or less familiar to the pupils, or which can be readily understood by them.

The Committee having agreed as to the principles on which a scheme of elementary instruction should depend, Prof. Armstrong undertook to prepare a series of suggestions for an actual course of instruction in sufficient detail to serve as a general guide to teachers. These suggestions form a part of the Committee's Report, and are of very considerable importance. The course is divided into six "stages." Stage I. deals with lessons on common and familiar objects; the classification of these according to their uses and origin; elementary physiography and Naturkunde. Stage II., with lessons in measurement. Stage III., with studies of heat on things in general; of their behaviour when burnt. Stage IV., the problem stage-to determine what happens when iron rusts; to determine the nature of the changes which take place when substances are burnt in air ; to separate the active from the inactive constituent of air ; to determine the composition of chalk; to determine what happens when organic substances are burnt; to determine what happens when sulphur is burnt ; to determine what happens when metals are heated with acids; to determine what happens when oxides are treated with acids; to determine what happens when the gas obtained by dissolving iron and zinc in sulphuric acid or muriatic acid is burnt ; to determine what happens when hydrogen and other combustible substances are heated with oxides; to determine whether oxides, such as water and chalk gas, may be deprived of oxygen by means of metals; to determine the composition of salt-gas and the manner in which it acts on metals and oxides; to determine the composition of washing-soda. Stage V., the quantitative stage : study of the quantitative composition of some of the substances which have already been qualitatively examined. Stage VI., studies of the physical properties of gases in comparison with those of liquids and solids; the molecular and atomic theories, and their application.

Without pledging themselves to accept every detail, many of which would naturally be modified by teachers to suit their own special cirumstances, the Committee state that Prof. Armstrong's suggestions are typical of the kind of instruction which they wish to see generally introduced into schools. They prefer to speak of it as a course of elementary instruction in "physical science," since, although it is mainly chemical, physical problems are largely introduced, and the course, as a whole, may be looked upon as a suitable introduction to the study of any of the physical sciences.
In bringing this scheme under the notice of teacher, the Committee make several recommendations as to the manner in which it should be carried out, but these can only be briefly alluded to here. They insist that the instruction should be commenced with young children, and that every pupil in the school should receive it. In order that it may be successful, a fair share of the school time must be devoted to the subject, and a larger number of teachers must be employed than is now usually the case. While this may lead to some extra expense, on the other hand it is pointed out that the simplest laboratory fittings and apparatus are all that will actually be needed. Thus the expenditure attending the adoption of the new course need not be greater than it is now in those schools where science teaching occupies a prominent place among the subjects of study.

Space does not allow of more than a passing mention of the series of statistics in reference to the teaching of chemistry in public elementary schools which have been admirably collected and commented upon by Prof. Smithells, and which form the second part of the Report. As in the higher public schools, the teaching of elementary science in these institutions is shown to be far from satisfactory, and here also a scheme of the kind suggested by the Committee might be introduced with very great advantage.

In the discussion which followed the reading of the Report the Committee had the satisfaction of learning that their recommendations receive the approval of several teachers of experience. A representative of Section $E$ stated that those interested in the efficient teaching of geography felt strongly that the course of work advocated by the Committee was on the proper lines. The head master of a large elementary school complained of the present methods of teaching chemistry, and stated that they tended so strongly towards making those who followed them into professional and technical chemists, that he had been obliged to substitute for chemistry instruction in some other branch of science. A useful contribution to the discussion was made by a former assistant science master in one of the largest public schools in London, who gave a graphic account of the hardships which were suffered by the solitary science master and his assistant in their efforts to teach "practical chemistry" to large classes of boys. If the comparison he instituted between the methods respectively adopted in this school in teaching classics and science be true, and if his statistics are correct as to the number of boys who are "taught" science, and the number of masters employed to teach them, they reveal a scandalous state of affairs, which no City Company ought to tolerate in a school which it endows. Finally, Prof. Armstrong read: letters which he had received from Prof. Huxley, the head master of Rugby, Sir Philip Magnus, and other authorities, in which they spoke with approval of the scheme for science teaching which the Committee advocate in their Report.

It seems likely, then, that through the action of this Committee a considerable impetus in a new direction will be given to the elementary teaching of science in this country. The words which Mark Pattison wrote more than twenty years ago are as true now as they were ther, and may appropriately bring these remarks to a con- 
clusion. "The dispute between science versus classics in education will not be settled on paper or by discussion. It will be settled, in fact, by the establishment somewhere or other, and in some form or other, of a system of scientific education, the results of which will vindicate themselves. We may argue, and vested interests may resist, but the tendency of things is unmistakable-the sciences will end by conquering their place."

W. R. D.

\section{CORRESPONDENCE OF CHRISTIAN HUYGENS.}

Euvres Complètes de Christiaan Huygens. Publiées par la Société Hollandaise des Sciences. Tome Deuxième : Correspondance, I657-59. (La Haye : Martinus Nijhoff, I889.)

' $\mathrm{HE}$ second volume of the great edition of Huygens's works, the first volume of which was noticed last year in these pages (NATURE, vol. xxxviii. p. I93), has made its appearance with creditable promptitude. The letters included in it range from $I 657$ to 1659 . That they are numerous and elaborate is sufficiently shown by the bulk of their receptacle; their value might be taken on trust from the names of the writers, and can be ascertained by the somewhat laborious process of perusal. This, however, may be curtailed at pleasure by having recourse to a series of admirably-constructed indexes, aided by which, readers, exempted from the ignominious necessity for "skipping," are enabled to find what they want, and neglect what less immediately concerns them.

Scientific correspondence was in those days of far greater importance than it is now. It, in fact, to a great extent, took the place of scientific journalism. There was then no recognized channel of public criticism. The first numbers of the Philosophical Transactions and the Journal des Savans appeared within a few months of each other in 1655 ; the Acta Eruditorum began to be published at Leipzig only in 1682. The learned formed a cosmopolitan caste, using a cosmopolitan language. They made an audience "fit and few" for each other's communications, and cared little, in general, to addiress a wider public. Epistolary intercourse assumed, accordingly, proportions and a significance which we find it difficult to realize. From one end of the Continent to the other, workers were, by means of letters nominally private, kept au courant of the progress of invention, readers of the course of publication; ideas and criticisms were interchanged; authors were informed of the impression produced by their works ; controversies were conducted or commented upon.

In the correspondence now before us, indeed, there is small trace of the odium scientificum. Although often obliged to stand on the defensive against unjust attacks upon his originality, Huygens never lost self-control. The scelerata insania belli had no place in his calm and reasonable mind. His reticence is strikingly illustrated by the incident of the feigned anagram, left unfinished and mysterious by the earlier letters, but brought to a satisfactory conclusion in the present collection. The bogus claim put forward by Dr. Wallis to the detection of Saturn's first-known satellite, proves, in accordance with the conjecture emitted by $\mathrm{Mr}$. Maunder in the Observatory for last March, to have been an infelicitous practical joke. It enforced, however, a designed moral by rendering palpable the protective inefficacy of crytographical announcements; and no more was heard (that we are aware) of the entrenclsment of discoveries or inventions behind logogryphs. Huygens continued in a state of mystification on the point for above three years, the Savilian Professor's first explanatory letter having miscarried; but he allowed his natural irritation only the vent of a few jottings of a strictly private character.

The publication of Huygens's "Systema Saturnium" was the leading event of the period now under consideration. The book was long and eagerly expected, and was received-so far as letters acknowledging the receipt of "complimentary copies" enable us to judge-with a chorus of approbation. Its author, at the age of thirty-Galileo being already dead, and Newton as yet un'nown-found himself pre-eminent among the astronomers of Europe. "Ora ha Giotto il grido." Yet the flattering assurances with which he was overwhelmed did not wholly exclude some expressions of misgiving. The physical and mechanical difficulties attending the existence of such a Saturnian system as he described were very great. The hypothesis of a ring was no doubt beautifully ingenious, and accounted for observed phenomena with the utmost neatness and sufficiency; but was it true? Was such an incredible structure, in point of actual and undeniable fact, to be found in the heavens? Su:h questionin ss could not but arise, and were only finally set at rest by the predicted complete disappearance of the anomalous appendages as the earth got to the unilluminated side of them towards the end of $167 \mathrm{I}$.

Saturn's ring-system has now so long held a place in astronomical consciousness that it costs an effort of the imagination to conceive the audacity of the first attempt to establish it there. Its author himself did not look for immediate and unqualified assent. All he hoped for was that his mode of accounting for the "bizarre appearances" of the "triple planet" should get an unprejudiced trial. Writing to Slusius in September 1659, he congratulated himself that his hypothesis had not struck him as absurd; and he met the scruples of objectors with a quiet appeal to time. It has not failed to justify his confidence.

An incidental paragraph in the "Systema Saturnium" (p. 9), announcing the virtual discovery of the great Orion nebula, appears to have excited little attention. Huygens's correspondents passed it over in silence; he took no trouble to invite their opinions on the subject ; nor is there evidence that any of his subsequent objervations were directed towards that "gap " (as it were) in the crystalline vault through which the glimmering of empyreal fire was discernible. Still more singularly, Hevelius, although he catalogued the stars, and enumerated fourteen nebulæ, did not include among them the Orion " portent," upon which, indeed, he seems never to have had the curiosity to direct his teles sope (H. Schultz, Astr. Nach., No. I585). The first intelligent observer of nebula was Halley.

A sidereal phenomenon of another sort, however, attracted considerable attention in the learned coteries of Paris and the Hague. Janson's "new star," in collo Cygni, was again visible in $1658-59$ First seen in $16 \mathrm{co}$ as of the third magnitude, it disappeared from view 